\title{
TOTALMENTE DEMAIS E AS EXPERIMENTAÇÕES DA TV GLOBO
}

\author{
Totalmente Demais and TV Globo experiments \\ Totalmente Demais y las experimentaciones de la TV Globo
}

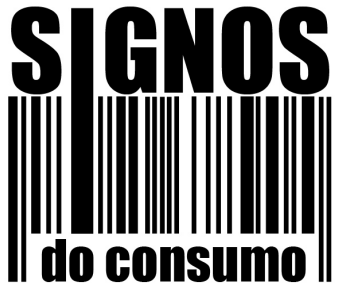

artigo

\author{
Gabriel Souza \\ Universidade Federal de Santa Maria, Rio Grande do Sul, Brasil. \\ Publicitário, doutorando em Comunicação Midiática na Universidade Federal de Santa Maria. \\ E-mail: gabrields92@hotmail.com
}

\section{Maria Lília Dias de Castro}

Universidade Federal de Santa Maria, Rio Grande do Sul, Brasil.

Professora do Programa de Pós-Graduação em Comunicação da Universidade Federal de Santa Maria. Doutora em Comunicação pela Universidade de Paris III - Sorbonne Nouvelle. Coordenadora da pesquisa Comunicação Televisual (COMTV).

E-mail:mlilia@terra.com.br

\section{Fernanda Sagrilo Andres}

Universidade Federal do Pampa, Rio Grande do Sul, Brasil.

Relações Públicas. Doutora em Comunicação. Docente da Universidade Federal do Pampa e integrante do Grupo de Pesquisa em Comunicação Televisual (COMTV).

E-mail:fersagrilo@gmail.com

RESUMO A proposta deste trabalho é averiguar as inovações lançadas pela emissora TV Globo, mais especificamente na telenovela Totalmente Demais, buscando mapear as estratégias empregadas no plano intertextual, no que se refere às novas experiências de conteúdo, às possibilidades de interatividade com o público telespectador e aos diferentes recursos de apelo comercial, dentro do contexto da convergência midiática. Trata-se de reflexão baseada na construção discursiva e, como tal, centrada na teoria semiótica de filiação greimasiana e nos desdobramentos propostos pelo Grupo de Pesquisa em Comunicação Televisual (COMTV) da UFSM.

PALAVRAS-CHAVE Televisão, Telenovela, Estratégias, Semiótica.

ABSTRACT The proposal of this work is to investigate innovations launched by TV Globo broadcasting, more specifically in the telenovela Totalmente Demais, seeking to map the strategies employed in the intertextual plane, regarding new experiences of content, possibilities of interactivity with the viewer and different resources of commercial appeal, in the context of media convergence. It is a reflection based on the discursive construction and, as such, centered on the semiotic theory of greimasian affiliation and on the developments proposed by the Research Group on Televisual Communication (COMTV) of UFSM.

KEYWORDS Television, Soap opera, Strategies, Semiotics.

RESUMEN El propósito de este estudio es investigar las innovaciones lanzadas por la emisora TV Globo, específicamente en la telenovela Totalmente Demais, tratando de identificar las estrategias empleadas en el plan intertextual en relación con las nuevas experiencias de contenido, las posibilidades de interactividad con el público espectador y los diferentes recursos de apelación comercial en el contexto de la convergencia de medios. La reflexión es basada en la construcción discursiva y, por lo tanto, centrada en la pertenencia de la teoría semiótica greimasiana y en los desarrollos propuestos por el Grupo de Investigación en Comunicación Televisiva (COMTV) de la Universidad Federal de Santa Maria (UFSM).

PALABRAS CLAVE Televisión, Telenovela, Estrategias, Semiótica. 


\section{INTRODUÇÃO}

Por muito tempo, os pressupostos da revolução digital previam que o surgimento de uma nova mídia implicaria o desaparecimento da mídia anterior. Diferentemente do que se pensava, hoje cada vez mais existe aproximação entre novas e antigas mídias. É nesse sentido que, para Jenkins (2009), esse fenômeno, denominado Cultura da Convergência, não apenas se destaca pelos aparatos tecnológicos que introduz, como possibilita distintas atividades interativas, conferindo outra dimensão à relação entre consumidores e produtores.

É importante também ressaltar que, por mais que a televisão assuma protagonismo e detenha a maior fatia do bolo publicitário, a chegada de distintas plataformas tem trazido ao público possibilidades variadas de acesso e multiplicidade de conteúdos, o que compromete, diretamente, a audiência da mídia televisual.

Dentro desse cenário, a televisão brasileira, em especial a emissora Globo, vem recorrendo a diferentes inovações para consolidar o antigo predomínio de audiência nos canais abertos, com seu propalado "padrão de qualidade". Para tanto, a emissora adota uma imensa gama de experimentações que vão da escolha da voz que traduz o perfil da emissora, até modificações substantivas na grade, passando por ações estratégicas voltadas ao bem-estar do público e à valorização da marca.

Nessa medida, o objetivo desta comunicação é investigar o ineditismo experimentado por uma produção da TV Globo - a telenovela Totalmente Demais - nesses novos tempos de mobilidade e interatividade digital. E essa escolha, em um primeiro momento, prende-se à necessidade de, como sugere Fechine (2009, p. 141), "pensar os novos conteúdos para TV a partir da própria TV”.

Assim se justifica o interesse desta proposta em pautar a discussão na própria produção para reconhecer os movimentos nela adotados, na tentativa de estabelecer vínculos com um telespectador mais familiarizado com outras plataformas. O artigo, centrado na pesquisa qualitativa, com teoria e método semiótico de origem greimasiana, voltase para a identificação das estratégias de natureza intertextual, sobretudo no que se refere à utilização de outros textos e plataformas para firmar parceria com o público.

Nesse sentido, a proposta está dividida nas seguintes partes: um panorama de fundo que discute essa televisão em busca de adaptação aos novos tempos; uma síntese teórica que explicita alguns princípios fundadores da teoria que sustenta esta reflexão; uma análise, na perspectiva das estratégias relacionadas, referente ao plano intertextual; uma reflexão sobre o movimento adotado e as repercussões trazidas pela telenovela Totalmente Demais da TV Globo nesses tempos de interatividade digital.

\section{TELEVISÃO: MÍDIA EM CONSTANTE ADAPTAÇÃO}

O estudo em torno dessa mídia remete, de início, ao aspecto evolutivo da televisão, que, para Eco, está dividido em duas grandes fases: a paleotelevisão e a neotelevisão. A primeira, referente ao período anterior aos anos 1970/1980, está relacionada às escolhas estratégicas que o meio realizava para produzir e veicular produtos, sempre utilizando o mundo exterior como pano de fundo, para reforçar a inter-relação 
produção/recepção. A outra, referente aos anos 1980/1990, dá importância ao mundo interior, o que corresponde à fala da televisão centrada em si mesma, ou seja, à ênfase ao eixo da própria produção.

Nos dias de hoje, sobretudo depois de significativos avanços tecnológicos, parece configurar-se uma nova dimensão, iniciada por volta de 2000 (DUARTE, 2016, p. 77), que se pauta pela chegada da tevê digital. Esse período também é denominado hipertelevisão ou metatelevisão, referente à maior proximidade entre televisão e internet e à interatividade mediada pelos aparelhos celulares. É nessa esteira, também, que Missika (2006) propõe a denominação de pós-televisão, por não haver uma clara distinção entre produção e recepção em televisão. Esse novo ambiente de televisibilidade é marcado, basicamente, pelo compartilhamento de vídeos, pelo streaming e pelo consumo sob demanda, reforçando o embaralhamento entre as instâncias de produção e recepção.

Cabe ressaltar que as constantes alterações por parte dessa mídia confirmam o pensamento de França (2009, p. 28) de que "a televisão e isto desde seu início - se modifica continuamente; modifica-se acompanhando mudanças tecnológicas e sociais mais amplas, e ainda conforme a dinâmica cultural de cada sociedade”. Além disso, qualquer discussão voltada à televisão no país precisa ressaltar que ela acumula a configuração de veículo de comunicação e a de empresa comercial, o que determina também a relação necessária e dependente com os anunciantes, em virtude da condição de provedora do próprio negócio.

Dessa forma, alinhando o incremento das novas tecnologias com a assumida duplicidade de papéis, a tevê passa a dividir espaço com as outras telas, tanto para levar informação, entretenimento e educação ao público como para cumprir o papel de empresa privada que precisa reforçar o próprio fazer e valorizar sua marca. Hoje, por exemplo, ela compete com o telefone celular, que além de ser usado para fazer ligações, enviar mensagens ou fotografar, permite que o usuário assista aos programas de televisão e também acesse a internet e as redes sociais digitais, ou faça download de filmes, vídeos e músicas.

A partir dessa pluralidade de ofertas, a consequência natural para a mídia televisual, e logo para a TV Globo (não obstante seu padrão de qualidade), tem sido a gradativa perda de audiência, o que preocupa sobremaneira seus produtores. Horários até então consolidados estão perdendo público: a telenovela das $21 \mathrm{~h}$, por exemplo, que sempre foi o carro-chefe da emissora, registrou em abril de 2015, nas primeiras semanas de lançamento (telenovela Babilônia), perda de público para a telenovela das $19 \mathrm{~h}^{1}$; o Jornal Nacional, telejornal mais conhecido do país, teve, em abril de 2015, a pior audiência dos últimos anos ${ }^{2}$.

De forma paradoxal, a queda de audiência na televisão aberta contrapõe-se ao crescimento diário do mercado de televisão por assinatura. De acordo com a Associação Brasileira de Televisão por Assinatura (ABTA), o número de assinantes dessa modalidade de tevê, no terceiro trimestre de 2014, cresceu 10,5\%, se comparado ao mesmo período de $2013^{3}$. Além disso, de 2006 a 2014, a quantidade de assinantes pulou de aproximadamente 4,7 milhões para 19,6 milhões de brasileiros. Em 2015, devido à crise

1. Disponível em: <https://goo.gl/53nMZY>. Acesso em: 10 dez. 2017.

2. Disponível em: <https://goo.gl/FakyYg>. Acesso em: 10 dez. 2017.

3. Disponível em: <https://goo.gl/zs6yWN>. Acesso em: $10 \mathrm{dez} .2017$. 
econômica, o número caiu para 19,1 milhões, enquanto só o primeiro semestre de 2016 fechou com 18,9 milhões de assinantes.

Nesse contexto de múltiplas ofertas, o telespectador pode encontrar outras possibilidades: só a empresa Netflix oferece, desde 2010, o seu serviço de televisão por internet em mais de cinquenta países, com um público total de 50 milhões, dos quais 2,2 milhões estão em solo brasileiro. O serviço inclui amplo catálogo de filmes e séries de tevê acessíveis em várias plataformas: televisão, notebooks, tablets e smartphones.

Todo esse movimento, fruto da digitalização, está alterando totalmente a forma de ver e fazer TV, que se transformou de tela exclusiva em tela simultânea, com iguais condições de interação, informação e comunicação. Confirma-se o pensamento de Montez e Becker (2005, p. 7) de que "a televisão - assim como qualquer outra mídia ou veículo de comunicação - também está envolvida num constante processo evolutivo e de adaptação às novas tecnologias e necessidades sociais”.

Constata-se, inclusive, que tevê e internet estão vivendo uma relação harmoniosa: "sua onipresença, sua convivência amigável, sua adaptabilidade às diferentes situações garante seu sucesso e sua permanência” (FRANÇA, 2009, p. 28). Naturalmente, para alcançar esse patamar a mídia televisual precisa apropriar-se dos recursos disponíveis, repensar o contexto midiático e reinventar-se constantemente.

Se, no âmbito televisual, a telenovela constitui uma narrativa veiculada em capítulos sequenciais, resultante da adaptação de algum livro, da recorrência a outros textos, da referência a distintas tramas; no plano tecnológico, a reprodução dessa história permite a sincronização de telas (não apenas da tevê) e a configuração plural decorrente das diferentes plataformas.

Entre as escolhas possíveis nesse novo cenário de mobilidade, portabilidade e interatividade digital (MATTOS, 2010), os recursos disponibilizados envolvem sites oficiais, blogs de personagens e dos autores das telenovelas, páginas no Facebook, perfis no Twitter, contas no Instagram, aplicativos para celular e narrativas em plataformas digitais de vídeos, sempre com o objetivo de acompanhar os avanços tecnológicos, estimular a interatividade e consolidar a imagem da emissora.

É justamente nessa direção que este trabalho está estruturado: investigar como a trama ficcional da telenovela escolhida tem buscado inserir alterações, seja recorrendo a outros textos, seja replicando a história em outras plataformas, com a intenção de estimular a interatividade com o telespectador/usuário, para conseguir despertar o interesse do público e, em consequência, aumentar os índices de audiência da emissora.

Nesse caminho, e dado o âmbito deste trabalho, torna-se relevante o reconhecimento dos movimentos estratégicos desenvolvidos no nível da intertextualidade, o que implica o detalhamento das estratégias relacionadas a esses outros textos e plataformas, convocados pela telenovela para captação do público.

\section{APORTE TEÓRICO-METODOLÓGICO}

Os textos televisuais convocam, simultaneamente, para sua expressão, distintas linguagens, as quais são perpassadas por outras, tornando esses 
textos cada vez mais complexos. É nesse contexto que se recupera o objetivo da semiótica greimasiana, a qual busca explicar o que o texto diz e como faz para dizer o que diz (GREIMAS, 1998). Assim, tomando como objeto de estudo o próprio texto, entendido como um rico objeto que mescla linguagens sonoras e visuais, a semiótica fundada por Algirdas Julien Greimas busca entender como nele se articula o sentido, levando em conta as instâncias de produção e de recepção.

No entendimento da teoria, o texto é produto de uma determinada ação que ultrapassa as fronteiras de materialização e, como tal, estabelece relação com o entorno em que está inserido, com outros textos a ele relacionados e com as articulações existentes em seu próprio interior. Assim, todo texto reflete um contexto que lhe serve de pano de fundo; é construído em resposta a um texto anterior, com a proposta de esclarecer, contrapor ou julgar e, assim, atualizar outras falas em novos espaços; e estrutura-se internamente em categorias discursivas responsáveis pela indicação, entre outras, de tema, espaço e tempo.

Cada discurso reitera, refuta, confirma, complementa e depende de outros; é sempre formulado em resposta a um estado de coisas, está sempre relacionado a outros discursos, uma vez que é resultado de uma interação verbal: de um lado, revela a posição do enunciador; de outro, expressa as posições responsivas, avaliativas, que lhe ficam subjacentes. (DUARTE; CASTRO, 2014, p. 79)

Essa é a base teórica das investigações desenvolvidas pelo Grupo de Pesquisa em Comunicação Televisual (COMTV) ${ }^{4}$. No entendimento do grupo, o texto televisual, além de estabelecer relações com o mundo exterior, também se relaciona com o mundo interior, o próprio fazer, ou com outras mídias, que são convocados a participar e a compor um novo texto. Dessa forma, projetam-se três níveis possíveis de análise: o paratextual (amplo e restrito), o intertextual (paradigmático e sintagmático) e o intratextual.

Dadas as características deste trabalho, adotou-se como nível de pertinência o plano intertextual sintagmático, o que, segundo Duarte e Castro (2014, p. 78), “compreende a interação de um produto midiático com outros textos, midiáticos ou não, dando conta de reiterações e/ou apropriações de outras vozes, que nele se atualizam, e o reconhecimento do que o precede e sucede”. Isso implica, então, a investigação da telenovela Totalmente Demais quanto à utilização de estratégias relativas à referência a outros textos, apropriação de fragmentos, transposição de personagens e até mesmo reapresentação que um texto faz de outros textos, ressignificando-os e/ou atribuindo-lhes novos sentidos.

\section{EXPERIMENTACÕES EM TOTALMENTE DEMAIS}

No exame de Totalmente Demais, obedecendo à perspectiva analítica da semiótica greimasiana, apresenta-se um detalhamento preliminar da telenovela e, na sequência, especificam-se as estratégias utilizadas pela emissora no plano da intertextualidade, que constituem as experimentações “totalmente demais” convocadas, na relação com outros textos.

4. Grupo de pesquisa do Programa de Pós-Graduação em Comunicação (PPGCOM) da Universidade Federal de Santa Maria, liderado pelas pesquisadoras Elizabeth Duarte e Maria Lília Dias de Castro, voltado ao estudo da produção televisual. 


\section{Detalhamento da trama}

Totalmente Demais, exibida pela TV Globo de 9 de novembro de 2015 a 30 de maio de 2016, foi escrita por Rosane Svartman e Paulo Halm $^{5}$. Com direção geral de Luiz Henrique Rios ${ }^{6}$, marcou uma nova fase de conteúdo "multiplataforma” produzido pela TV Globo, o que lhe permitiu receber as indicações ao Troféu Internet de 2016 por Melhor Novela, Melhor Atriz e Melhor Ator, premiação que indica os melhores artistas da televisão e da música brasileira do ano anterior, apresentada durante a 55 a edição do Troféu Imprensa, no dia 26 de maio de 2016, no SBT.

A trama, protagonizada por Marina Ruy Barbosa (Eliza), Fábio Assunção (Artur) e Felipe Simas (Jonas), contava a história da jovem Eliza, que fugiu de casa em busca de uma vida melhor para si e com a promessa de que, assim que conseguisse um bom emprego, traria a mãe e os dois irmãos para morarem com ela.

\section{Estratégias empregadas}

Ao longo da trama, foram inúmeros os artifícios utilizados em relação a outras narrativas, a diferentes plataformas, à configuração do telespectador/usuário e à utilização de parceiros comerciais, e todos esses movimentos garantiram à telenovela audiência até então inédita.

\section{Recorrência ao conto maravilhoso}

A telenovela centrou-se claramente na trama de uma jovem infeliz que, obrigada a fugir de casa devido ao assédio do padrasto, viu-se tal qual a "gata borralheira", abandonada à própria sorte. Sendo moradora de rua, que vendia flores em bares e restaurantes, conheceu o "príncipe encantado” (empresário Arthur, dono da agência de modelos Excalibur) que a transformou em modelo de sucesso. Depois de encontros e desencontros, típicos da trama telenovelística, ela acabou encontrando o sucesso pessoal, a tranquilidade financeira e o verdadeiro amor de sua vida.

\section{Embaralhamento realidade/ficção}

No meio da trama ficcional, a diretora de redação da revista Glamour, Mônica Salgado, participou de uma cena em que convida a protagonista Eliza a ser capa da revista, o que de fato ocorreu quando a atriz Marina Ruy Barbosa foi exibida na edição de março de 2016. A mistura dos planos de realidade e ficção trouxe, com certeza, outro espaço de visibilidade à revista e conferiu maior reconhecimento à telenovela. Com essa iniciativa, comprovam-se as palavras da diretora de que "as fronteiras estão derretidas hoje em dia. Então é muito interessante para uma marca como a Glamour poder chegar até as pessoas via TV aberta, numa novela que retrata o mundo da moda. Um crossmedia

5. As autoras ainda contaram com a colaboração de Claudia Sardinha, Fabrício Santiago, Felipe Cabral e Mário Viana e com a revisão de texto de Charles Peixoto.

6. A direção também contou com a colaboração de Luis Felipe Sá, Marcus Figueiredo, Noa Bressane e Thiago Teitelroit. 
enriquecedor para ambas as marcas"7. Essa estratégia, já utilizada em outras tramas, sempre garante resultados positivos, na medida em que a trama ficcional acaba ultrapassando o espaço da televisão e ganhando materialidade no mundo real.

\section{Apelo ao crossover (mistura de duas histórias)}

No último capítulo da telenovela Totalmente Demais, houve referência à trama que seria veiculada na sequência, naquele mesmo horário da grade (Haja Coração). No quinto bloco da telenovela, a personagem Fedora, interpretada por Tatá Werneck, atriz principal da telenovela estreante, parou o trânsito com sua Ferrari rosa pink, interpelou a personagem de Carolina Castilhos em um parque e pediu que sua foto fosse estampada na capa da revista Totalmente Demais. Carolina passou a palavra para Pietro Henrique, diretor da revista na trama, e disse que não a conhecia. Foi quando Fedora falou: "a partir de amanhã, todo o Brasil vai amar Isabel Abdalla”; entrou no carro e sumiu da cena (TOTALMENTE DEMAIS, 2015-2016).

A mesma estratégia serviu de gancho para exibir, ao término do último capítulo, um clipe da nova novela das $19 \mathrm{~h}$, com duração aproximada de cinco minutos, apresentando várias imagens dos cenários e atores, embalados pela música tema da nova atração. Também foram inseridos comentários dos atores, com explicações sobre seus personagens, e dos autores sobre a trama. Essa estratégia de crossover foi utilizada para familiarizar os telespectadores com a nova atração e tentar minimizar o estranhamento em relação ao novo produto, com o intuito principal de convocar a audiência e instigá-la ao consumo.

\section{Veiculação de capítulo em outras plataformas}

Tanto a estreia quanto a finalização de Totalmente Demais aconteceram pela internet: o Globo Play, plataforma de vídeo on demand da emissora, proporcionou um capítulo zero (antes da veiculação na televisão), para aproximar o público da nova trama, familiarizando-o com os personagens e temas abordados na telenovela. Da mesma forma, após a exibição do último capítulo, ainda foram veiculados dez episódios inéditos, intitulados “Totalmente Sem Noção Demais”, patrocinados pela marca de esmaltes Risqué, no Gshow e no app Globo Play. De acordo com o Gshow:

Para os fãs que já estão com saudades antecipadas de Totalmente Demais, o Gshow e o Globo Play, plataforma de vídeo on demand da Globo, exibirão uma extensão da trama, de Rosane Svartman e Paulo Halm, com conteúdos inéditos. Sob o título 'Totalmente Sem Noção Demais', o spin-off terá 10 episódios exclusivos, que serão exibidos a partir da próxima terça-feira, 31/5. A obra vai contar histórias dos personagens Hugo (Orã Figueiredo), Cassandra (Juliana Paiva), Débora (Olívia Torres), Zé Pedro (Hélio De la Peña) e Dorinha (Samantha Schmütz) que se passaram um ano antes da trama que foi ao ar na TV. No Mais Você desta segunda-feira, 30/5, Juliana Paiva comentou a reta final de 'Totalmente Demais' e falou um pouquinho sobre as gravações do spin-off. "É a Cassandra ainda morando no Bairro de Fátima, sonhando ainda em ser modelo. É

7. Disponível em: <https://goo.gl/39ayKe>. Acesso em: 10 dez. 2017. 
ela se tornando a Cassandra!”, contou Ju. Mal podemos esperar! (GSHOW, 2016)

Esse movimento inaugural de lançar o capítulo zero e de oferecer desdobramentos da história finalizada teve a clara intenção, por parte da emissora, de mostrar o seu domínio tecnológico, replicar o conteúdo da trama em outras plataformas, surpreender o público (telespectador/usuário) e consolidar a audiência da emissora.

\section{Interpelação às redes sociais}

Ainda que outras telenovelas tenham recorrido ao mesmo movimento, a telenovela Totalmente Demais explorou com intensidade a interatividade com a internet para decidir o desfecho da trama, o que também contribuiu para o sucesso da atração. Na história, Eliza relacionou-se com Jonatas (Felipe Simas) e Arthur (Fábio Assunção), o que desencadeou uma mobilização de fãs na web, que se dividiam na torcida entre os dois casais com a utilização das hashtags \#JoLiza ou \#Arliza. Os fãs da telenovela moviam discussões nas redes sociais, com vistas à escolha do desfecho da história.

Na conta da telenovela na rede social Twitter (Figura 1), a hashtag \#TotalmenteDemais alcançou o Trending Topics do Twitter Brasil, com uma média de 139 mil tweets, até as 20h30. Ainda, outras hashtags muito utilizadas foram \#CarThur, \#JoLiza, \#ArLiza e \#Gabrielle. Logo após o término da telenovela, a foto que estampava a capa da conta de Totalmente Demais era a da sua sucessora, Haja Coração, reiterando e reforçando a marca e os personagens principais do novo produto da emissora.

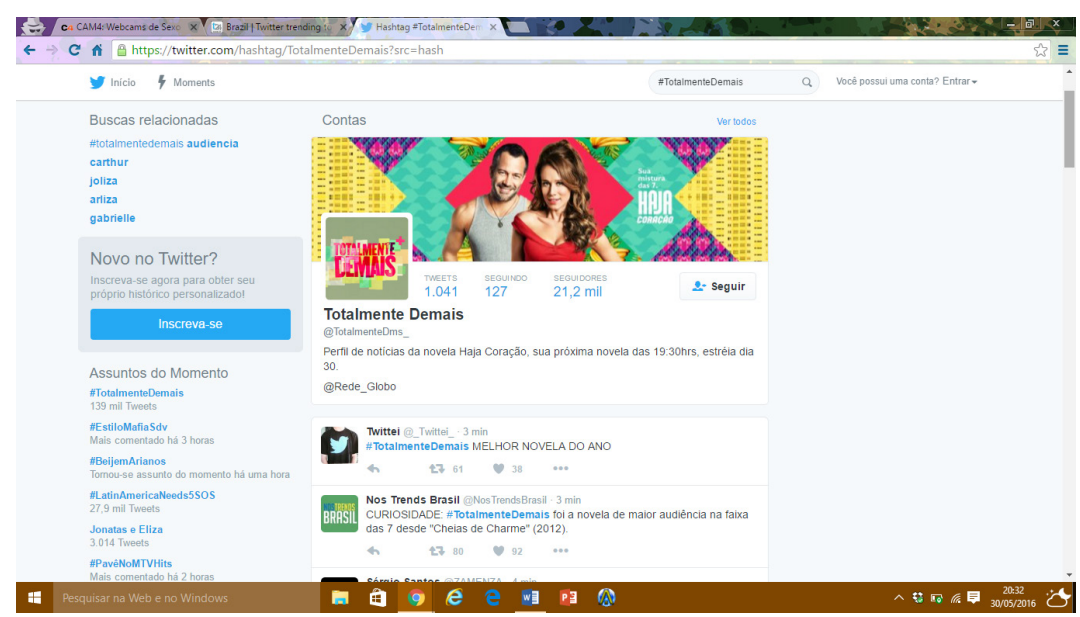

Figura 1. Conta de Totalmente Demais no Twitter.

Fonte: Twitter'.

\section{Transmissão ao vivo da rede social}

Durante a exibição do último capítulo, personagens, colaboradores e diretores emitiam comentários, em transmissão ao vivo pelo streaming do Facebook, na página do Gshow. 


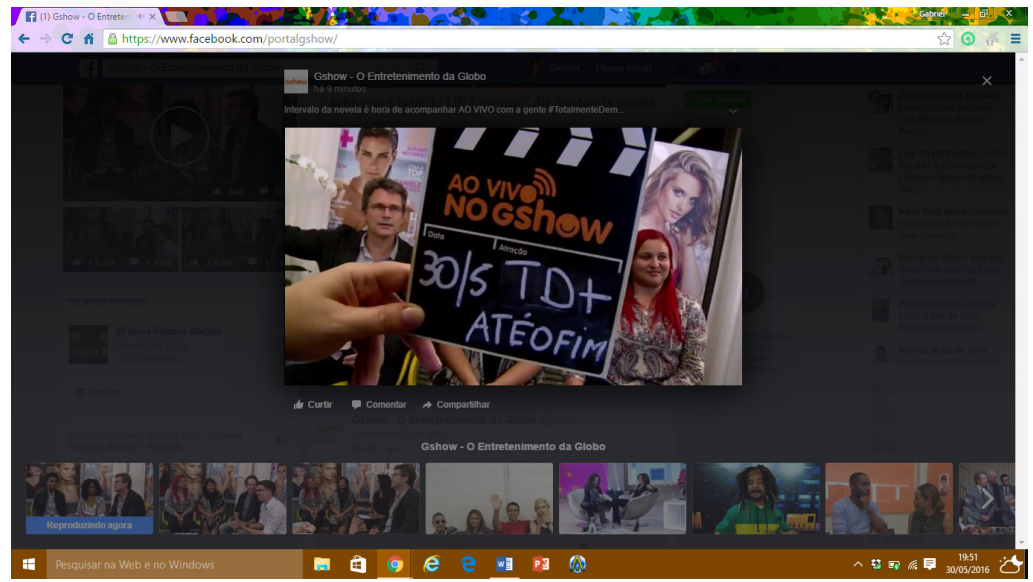

Figura 2. Transmissão pela página do Gshow no Facebook.

Fonte: Facebook (2016) $)^{9}$.

Enquanto na tela da tevê era exibido o capítulo final, na página do Gshow, em transmissão ao vivo, aparecia uma placa semelhante a uma claquete de cinema, com a data de exibição do último capítulo, 30/05, e os dizeres “Totalmente Demais até o fim” (Figura 2). Já no intervalo comercial da trama, apareciam os atores, os diretores e os colaboradores que estavam assistindo, juntos, ao capítulo, e que entravam ao vivo no Facebook para emitir opiniões sobre o episódio, sobre sua contribuição com a telenovela e sobre a trama em geral (Figura 3).

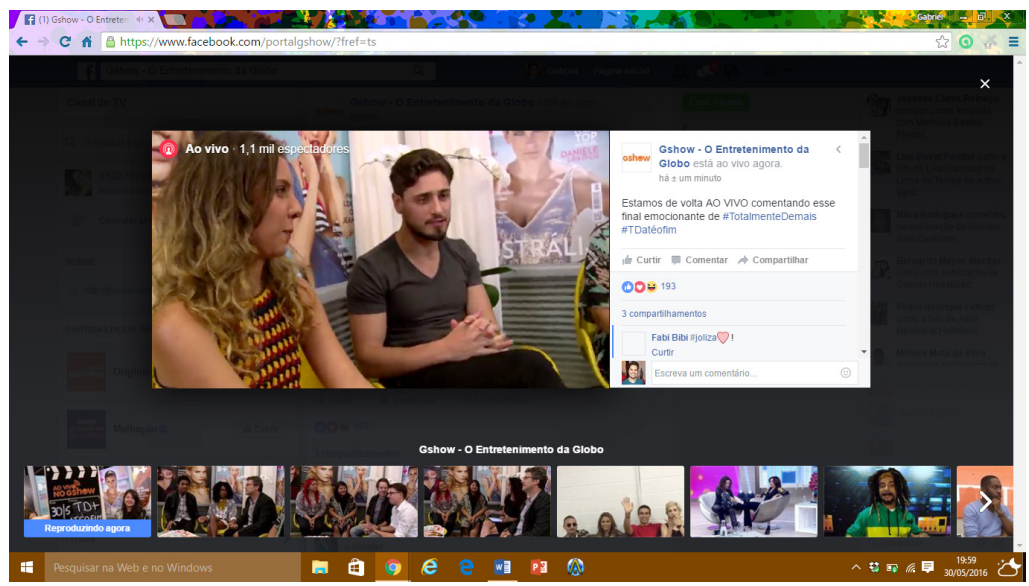

Figura 3. Fala dos atores no Facebook

Fonte: Facebook (2016)

\section{Reiteração das informações no portal}

No website do Gshow, o banner principal reforçava a atração da emissora, com três fotos assim direcionadas: uma imagem maior trazia o casal protagonista, com a indicação superior de "Final de 'Totalmente Demais", apresentando a referência "Eliza e Jonatas vivem romance em Paris”; uma imagem menor da atriz principal, com a indicação superior de "Totalmente sem noção demais" e a referência sobreposta "Cassandra é estrela do spin-off, veja teaser"; e uma imagem menor do casal protagonista da próxima novela, com a indicação superior de “"Haja

9. Disponível em: <https://goo.gl/US9PDG>. Acesso em: 10 dez. 2017.

10. Disponível em: <https://goo.gl/US9PDG>. Acesso em: 10 dez. 2017. 
coração' vem aí” e a referência sobreposta “Conheça os personagens e a história da nova das 7" (Figura 4). Essa estratégia de reiteração da trama teve a finalidade de replicar o conteúdo do núcleo principal e de expandir a força dos personagens em outras plataformas.

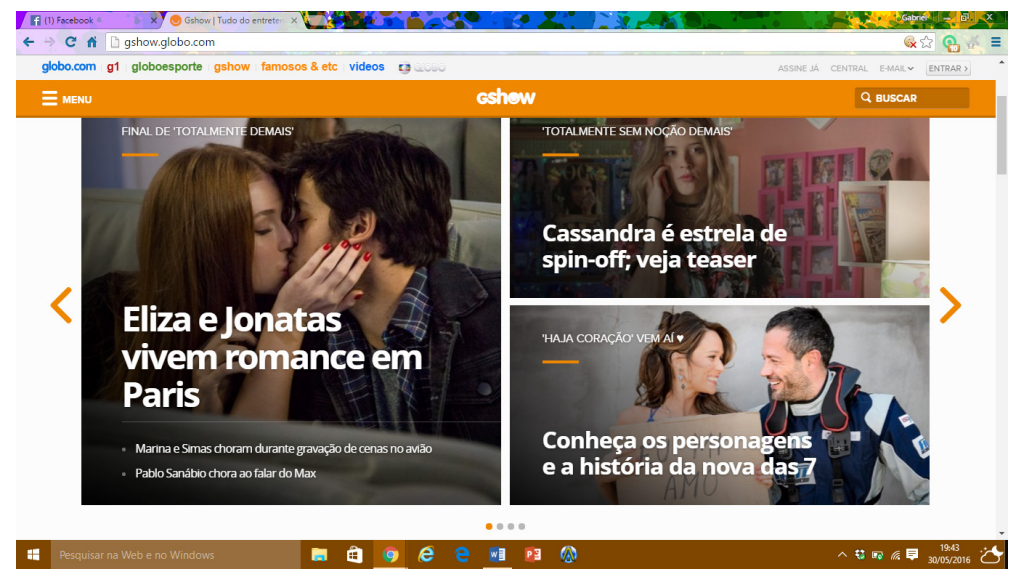

Figura 4. Página do site Gshow

Fonte: Gshow (2016)"11.

\section{Ações de parceria com anunciante}

A expressiva audiência da atração e a consequente aceitação do público telespectador possibilitaram que o departamento comercial da emissora testasse novos formatos. A Globo, em parceria com a agência Lew'Lara|TBWA, promoveu a primeira ação de branded content realizada pela marca de esmaltes Risqué. De acordo com Márcio Oliveira, CEO e sócio da agência, a parceria com a marca foi o resultado da boa aceitação da trama, representada na proximidade oferecida com os telespectadores: "ficamos muito entusiasmados para criar algo totalmente moderno e up to date. Em paralelo, estamos bastante contentes pela parceria da Coty (Risqué) com a Lew'Lara|TBWA, resultado de pioneirismo nesse formato" (GLOBO, 2016).

No entendimento do anunciante, a parceria com a emissora revelou o perfil inovador e descontraído da marca. Segundo Regiane Bueno, diretora de marketing, a

Risqué é uma marca moderna e arrojada, por isso a decisão de participar de um projeto pioneiro como este. Entendemos que é importante ampliar o leque de comunicação com nossas consumidoras, abrindo um novo canal para informar sobre nossas novidades em primeira mão, inclusive para as clientes que estão, ao mesmo tempo, antenadas na Internet e na TV. (GLOBO, 2016)

Dessa forma, a estratégia de aliar a marca ao conteúdo Globo representou o "casamento" perfeito, e a marca ainda ofereceu conteúdo especial na página de Totalmente Sem Noção Demais no Gshow e ações de ativação nos capítulos do spin-off, consolidando a parceria inédita das marcas. 
Essas foram, em linhas gerais, as estratégias utilizadas pela emissora na tentativa de recuperar a relação da trama com outros textos.

\section{APONTAMENTOS FINAIS}

A proposta central deste trabalho buscou investigar as inovações empreendidas pela TV Globo, mais especificamente na telenovela das 19h, Totalmente Demais, no que diz respeito às novas experimentações da emissora para atrair o telespectador, hoje dividido entre múltiplas plataformas. Para tanto, foram mapeadas as estratégias empregadas de caráter intertextual, ou seja, do texto televisual em relação a outros textos, dentro do encaminhamento teórico-metodológico que sustenta a reflexão.

Nesse sentido, pode-se constatar que a recorrência à simplicidade narrativa do conto maravilhoso pode proporcionar uma transposição (DUARTE, 2016) da história tradicional para a tela da tevê e uma expansão para as outras plataformas, possibilitando as inúmeras experimentações da telenovela. Além dessa estratégia, outras tantas foram empreendidas pela emissora: embaralhamento entre a realidade e a ficção, envolvimento de outras histórias (crossover), veiculação de capítulo em outras plataformas, interpelação às redes sociais, transmissão ao vivo da rede social, reiteração das informações no portal e ações de parceria com anunciante. Todas essas movimentações, quando combinadas, renderam ao último capítulo da telenovela uma das maiores audiências desde 2010, com 37 pontos.

A aceitação da trama pelo público permitiu, também, que o último capítulo da telenovela terminasse em uma segunda-feira e que sua reprise fosse veiculada na Sessão da Tarde da terça-feira, rompendo a tradição de veicular o último capítulo na sexta-feira e reprisá-lo no sábado. As inovações da TV Globo renderam ainda, no ano de 2017, a indicação de Totalmente Demais ao prêmio de Melhor Novela no Emmy Internacional, considerado o Oscar da televisão mundial.

Percebe-se que o novo contexto social dos indivíduos interfere diretamente na maneira como se assiste à trama e se consomem os produtos televisuais. Nesse sentido, é possível afirmar que os novos públicos ainda assistem à televisão, de uma maneira diferente da tradicional: hoje, em plena era digital, o telespectador tem o poder de escolher ao que assistir, como assistir, onde assistir e o que fazer com o que é visto. Além de olhar, ele quer comentar e, se possível, participar diretamente naquilo que lhe é ofertado.

De acordo com Simon Tunstill (2016), especialista em promoção mecadológica da televisão no Reino Unido, o papel da televisão, nos dias de hoje, continua muito expressivo. E essa força é, fundamentalmente, de ordem social: as pessoas gostam de compartilhar, de ver tevê com os amigos, de comentar com eles no Twitter e no Facebook. Por isso é tão importante a fusão da internet com a telenovela: a possibilidade criada de linha de transmissão propõe um sofá virtual que constitui uma "quase" interatividade ao vivo.

Nesse movimento, as emissoras de tevê aberta apresentam um pouco de dificuldade porque, além de manter o telespectador tradicional, precisam atrair essa nova parcela de público mais familiarizada com as tecnologias atuais, conciliando, assim, antigas e novas estratégias. Nesse panorama, nenhuma emissora pode esquecer que a configuração atual de 
telespectador prevê a de tele-emissor, ou seja, de alguém que assiste à tevê em diferentes telas, simultâneas ou não, e que precisa, permanentemente, ser convocado a opinar sobre o encadeamento da narrativa, em um verdadeiro movimento de em-se-fazendo, próprio da pós-televisão.

\section{REFERÊNCIAS}

CARAPEÇOS, N. "A televisão está mudando", diz Simon Tunstill. Gauchazh.tv, Porto Alegre, 9 dez. 2016. Disponível em: <https://goo.gl/dbuhhg>. Acesso em: 10 dez. 2017.

DUARTE, E. B. No total, menos: a simplicidade como opção narrativa. Intexto, Porto Alegre, n. 37, p. 313-328, set.-dez. 2016.

DUARTE, E. B.; CASTRO, M. L. D. Produção midiática: o ir e vir entre teoria, metodologia e análise. In: BARICHELLO, E. M.; RUBLESCKI, A. S. Pesquisa em comunicação: olhares e abordagens. Santa Maria: Facos, 2014. p. 67-87.

FECHINE, Y. A programação da TV no cenário de digitalização dos meios: configurações que emergem dos reality shows. In: FREIRE FILHO, J. A TV em transição: tendências de programação no Brasil e no mundo. Porto Alegre: Sulina, 2009.

FRANÇA, V. A televisão porosa: traços e tendências. In: FREIRE FILHO, J. A TV em transição: tendências de programação no Brasil e no mundo. Porto Alegre: Sulina, 2009.

GLOBO reforça estratégia multiplataforma com spin-off de "Totalmente Demais". Adnews, São Paulo, 30 maio 2016. Disponível em: <https://goo.gl/azHCQi>. Acesso em: 10 dez. 2017.

GREIMAS, A. J. A propósito do jogo. Verso e reverso, São Leopoldo, n. 27, p. 119-123, jul.dez. 1998.

GSHOW. "Totalmente Demais" ganha spin-off com Cassandra; confira teaser. Globo.com, São Paulo, 30 maio 2016. Disponível em: <http://glo.bo/1qJyWGf>. Acesso em: 10 dez. 2017.

JENKINS, H. A cultura da convergência. São Paulo: Aleph, 2009.

MATTOS, S. História da televisão brasileira. Petrópolis: Vozes, 2010.

MISSIKA, J. L. La fin de la télévision. Paris: Seuil, 2006.

MONTEZ, C.; BECKER, V. TV digital interativa: conceitos e tecnologias. Florianópolis: Ed. da UFSC, 2005

TOTALMENTE Demais. Direção: Luiz Henrique Rios. Produção: Estúdios Globo. Intérpretes: Marina Ruy Barbosa; Fábio Assunção; Felipe Simas; Juliana Paes e outros. Roteiro: Rosane Svartman e Paulo Halm. Jacarepaguá: Rede Globo, 2015-2016. (175 episódios), son., color., HDTV 1080i. 